\title{
Projected Shifts in Köppen Climate Zones over China and Their Temporal Evolution in CMIP5 Multi-Model Simulations
}

\author{
Duo CHAN, Qigang WU*, Guixiang JIANG, and Xianglin DAI \\ School of Atmospheric Sciences, Nanjing University, Nanjing 210023
}

(Received 18 March 2015; revised 31 July 2015; accepted 27 August 2015)

\begin{abstract}
Previous studies have examined the projected climate types in China by 2100. This study identified the emergence time of climate shifts at a $1^{\circ}$ scale over China from 1990 to 2100 and investigated the temporal evolution of Köppen-Geiger climate classifications computed from CMIP5 multi-model outputs. Climate shifts were detected in transition regions (7\%-8\% of China's land area) by 2010, including rapid replacement of mixed forest (Dwb) by deciduous forest (Dwa) over Northeast China, strong shrinkage of alpine climate type (ET) on the Tibetan Plateau, weak northward expansion of subtropical winterdry climate (Cwa) over Southeast China, and contraction of oceanic climate (Cwb) in Southwest China. Under all future RCP (Representative Concentration Pathway) scenarios, the reduction of Dwb in Northeast China and ET on the Tibetan Plateau was projected to accelerate substantially during 2010-30, and half of the total area occupied by ET in 1990 was projected to be redistributed by 2040. Under the most severe scenario (RCP8.5), sub-polar continental winter dry climate over Northeast China would disappear by 2040-50, ET on the Tibetan Plateau would disappear by 2070, and the climate types in $35.9 \%$ and $50.8 \%$ of China's land area would change by 2050 and 2100 , respectively. The results presented in this paper indicate imperative impacts of anthropogenic climate change on China's ecoregions in future decades.
\end{abstract}

Key words: Köppen-Geiger climate classification, China, climate change, CMIP5, RCP scenarios

Citation: Chan, D., Q. G. Wu, G. X. Jiang, and X. L. Dai, 2016: Projected shifts in Köppen climate zones over China and their temporal evolution in CMIP5 multi-model simulations. Adv. Atmos. Sci., 33(3), 283-293, doi: 10.1007/s00376-015-5077-8.

\section{Introduction}

China has a population over 1.3 billion, the world's third largest land area, varied topography, and diverse ecosystems. Therefore, the impacts of projected climate changes are expected to be large (Yu et al., 2006; Ni, 2011). To estimate ecological changes, some studies have used climate model outputs to drive a specialized vegetation model that projects changes in vegetation cover based on temperature, precipitation and other factors such as surface runoff and soil feedback (Ni et al., 2000; Ma et al., 2014; Wang, 2014; Zhao and Wu, 2014; Cho et al., 2015; Pan et al., 2015). Vegetation models project the following changes in vegetation cover over China by the end of the 21st century: a northward shift of all forests, disappearance of boreal forest over northeastern China, new tropical forests, an eastward expansion of grassland, and a reduction in alpine vegetation ( $\mathrm{Ni}, 2011)$. Other studies, using Köppen or related climate classification to investigate possible shifts in climate zones over China (Xie et al., 2007; Baker et al., 2010; Shi et al., 2012), generally project similar decreases of boreal forest in northeastern China, evergreen forest in southeastern China, and alpine tundra over the Tibetan

\footnotetext{
* Corresponding author: Qigang WU

Email: qigangwu@nju.edu.cn
}

Plateau.

The Köppen climate classification scheme was developed to explain observed biome distributions, which have many sharp boundaries due to plant sensitivity to threshold values of average monthly temperature and precipitation and their annual cycle (Köppen, 1936), and each climate type is closely associated with certain prevalent vegetation species. While climate zones are not exact boundaries for all species, locations with a change in climate class are expected to experience the most noticeable ecosystem stress, such as widespread die-back of forests. Köppen or similar classifications have been extensively used to estimate the potential impacts of past and future climate on prevalent ecoregions on regional and global scales (e.g., Wang and Overland, 2004; Gnanadesikan and Stouffer, 2006; De Castro et al., 2007; Baker et al., 2010; Rubel and Kottek, 2010; Mahlstein et al., 2013; Feng et al., 2014; Almorox et al., 2015; Engelbrecht and Engelbrecht, 2015; Phillips and Bonfils, 2015; Rohli et al., 2015). The Köppen or related classification schemes can be applied to climate model output as a first-order index to assess possible past and future changes in ecosystem types on a grid-cell level (Peel et al., 2007; Mahlstein et al., 2013). Despite its simplicity, Baker et al. (2010) suggested that the Köppen climate types resemble the major vegetation types in China. Based on Köppen or related climate classifications, 
previous studies have shown that regions of temperate climate types are projected to expand, while regions of sub-polar and alpine climate types are projected to contract significantly over the national land area by 2100 , using projected changes in temperature and precipitation in China (e.g., Rubel and Kottek, 2010; Shi et al., 2012; Feng et al., 2014). Other findings include losses of subtropical humid climate in Southeast China and an almost unchanged arid climate in Northwest China by 2100 (Shi et al., 2012).

The present study extends previous large-scale and regional studies by investigating, with detailed temporal and spatial resolution, the temporal evolution of projected Köppen climate types over China, including the emergence time and rate of anthropogenic-related change in climate types, and the relative role of temperature and precipitation in projected climate shifts. Other considerations are as follows: First, China encompasses a variety of climate types, from southern tropical to northern boreal, and from eastern humid to western arid and alpine climates (Ni, 2011). Second, projected future climate changes are not uniformly distributed among different regions in China. For instance, under the $+8.5 \mathrm{~W} \mathrm{~m}^{-2}$ Representative Concentration Pathway (RCP) scenario (RCP8.5), warming is projected to be up to $1.5^{\circ} \mathrm{C}$ greater in northern and western regions than in southeastern areas (Xu and $\mathrm{Xu}, 2012$; also see Fig. 1). Annual precipitation increases in all areas, with the largest increases in southwestern regions (see Fig. 1b), but the greatest percentage increases are in northern and western regions (Xu and $\mathrm{Xu}, 2012)$. Third, vegetation cover in different regions demonstrates varying sensitivity to climate change. Ecosystems over western and northern China are found to be more vulnerable to a change in climate than those over eastern China (Ni, 2011), and low-latitude mountainous regions are more likely to experience a shift in climate types (Mahlstein et al., 2013).

Our study is complementary to previous studies that focused on projections of China's climate types. We further investigated the temporal evolution of Köppen-Geiger climate types in China by 2100, and it is hoped that our analysis will prove helpful in promoting public awareness of the impacts of anthropogenic climate change on China's ecoregions.

\section{Data and method}

\subsection{Data}

Monthly temperature and precipitation grids from the University of Delaware (Legates and Willmott, 1990a, 1990b) were used to calculate the observed Köppen climate type in each grid box using 1980-99 (the "base period") averages for each month of the year. The Delaware dataset was chosen mainly due to its high resolution $\left(1^{\circ} \times 1^{\circ}\right)$. Version 3.02 covers the period 1900-2010 and is derived from GHCN2 (Global Historical Climate Network) and additional data obtained by Legates and Willmott (1990a, 1990b) covering the entire terrestrial area, and represents the climatological distribution of temperature and precipitation well (Legates and
Willmott, 1990a, 1990b; Peterson et al., 1998). This dataset has been used in other studies of Köppen climate classification (Feng et al., 2014; Chan and Wu, 2015).

Simulated fields of temperature and precipitation through to 2100 were obtained from CMIP5 (Coupled Model Intercomparsion Project, Phase 5) simulations performed using 31 global climate models (Table 1). The model runs were forced by observed atmospheric composition changes (reflecting both anthropogenic and natural sources) from 1950-2005 (the historical data period), and by prescribed changes in greenhouse gases and anthropogenic aerosols from 2006 to 2100 following four different RCPs (RCP2.6, RCP4.5, RCP6 and RCP8.5) from 2006-2100 (Taylor et al., 2012). Under these scenarios, radiative forcings in 2100 are about 2.6 (after a peak value of 3.0 around 2040), 4.5, 6.0 and $8.5 \mathrm{~W} \mathrm{~m}^{-2}$ greater, respectively, relative to the preindustrial period, including most known forcing factors (compared with $1.75 \mathrm{~W}$ $\mathrm{m}^{-2}$ in 2000). The corresponding equivalent $\mathrm{CO}_{2}$ concentrations (expressing all other radiative forcings as added or subtracted $\mathrm{CO}_{2}$ amounts) in 2100 are projected to be about 470 (after a peak of 490 around 2040), 650, 850 and 1370 ppm (Van Vuuren et al., 2011). As in Mahlstein et al. (2013), for a specific model and scenario with multiple ensemble runs,

Table 1. Models and experiments used in each experiment.

\begin{tabular}{|c|c|c|c|c|c|}
\hline & Histori & TP? & $\mathrm{CP} 4$ & CP6 & $\mathrm{SP} 8.5$ \\
\hline ACCESS 1.0 & $\sqrt{ }$ & $\times$ & $\sqrt{ }$ & $\times$ & $\sqrt{ }$ \\
\hline ACCESS 1.3 & $\sqrt{ }$ & $x$ & $\sqrt{ }$ & $\times$ & $\sqrt{ }$ \\
\hline BCC-CSM1.1 & $\sqrt{ }$ & $\sqrt{ }$ & $\sqrt{ }$ & $\sqrt{ }$ & $\sqrt{ }$ \\
\hline BCC-CSM1.1(m) & $\sqrt{ }$ & $\sqrt{ }$ & $\sqrt{ }$ & $\sqrt{ }$ & $\sqrt{ }$ \\
\hline CCSM4 & $\sqrt{ }$ & $\sqrt{ }$ & $\sqrt{ }$ & $\sqrt{ }$ & $\sqrt{ }$ \\
\hline CESM1(CAM5) & $\sqrt{ }$ & $\sqrt{ }$ & $\sqrt{ }$ & $\sqrt{ }$ & $\sqrt{ }$ \\
\hline CMCC-CESM & $\sqrt{ }$ & $x$ & $x$ & $\times$ & $\sqrt{ }$ \\
\hline CMCC-CM & $\sqrt{ }$ & $\times$ & $\sqrt{ }$ & $\times$ & $\sqrt{ }$ \\
\hline CNRM-CM5 & $\sqrt{ }$ & $\sqrt{ }$ & $\sqrt{ }$ & $\times$ & $\sqrt{ }$ \\
\hline CSIRO-Mk3.6.0 & $\sqrt{ }$ & $\sqrt{ }$ & $\sqrt{ }$ & $\sqrt{ }$ & $\sqrt{ }$ \\
\hline CanESM2 & $\sqrt{ }$ & $\sqrt{ }$ & $\sqrt{ }$ & $\times$ & $\sqrt{ }$ \\
\hline FGOALS-g2 & $\sqrt{ }$ & $\sqrt{ }$ & $\sqrt{ }$ & $\times$ & $\sqrt{ }$ \\
\hline FIO-ESM & $\sqrt{ }$ & $\sqrt{ }$ & $\sqrt{ }$ & $\sqrt{ }$ & $\sqrt{ }$ \\
\hline GFDL-CM3 & $\sqrt{ }$ & $\sqrt{ }$ & $\sqrt{ }$ & $\sqrt{ }$ & $\sqrt{ }$ \\
\hline GFDL-ESM2G & $\sqrt{ }$ & $\sqrt{ }$ & $\sqrt{ }$ & $\sqrt{ }$ & $\sqrt{ }$ \\
\hline GFDL-ESM2M & $\sqrt{ }$ & $\sqrt{ }$ & $\sqrt{ }$ & $\sqrt{ }$ & $\sqrt{ }$ \\
\hline GISS-E2-H & $\sqrt{ }$ & $\sqrt{ }$ & $\sqrt{ }$ & $\sqrt{ }$ & $\sqrt{ }$ \\
\hline GISS-E2-R & $\sqrt{ }$ & $\sqrt{ }$ & $\sqrt{ }$ & $\sqrt{ }$ & $\sqrt{ }$ \\
\hline HadGEM2-CC & $\sqrt{ }$ & $\times$ & $\sqrt{ }$ & $\times$ & $\sqrt{ }$ \\
\hline HadGEM2-ES & $\sqrt{ }$ & $\sqrt{ }$ & $\sqrt{ }$ & $\sqrt{ }$ & $\sqrt{ }$ \\
\hline INM-CM4 & $\sqrt{ }$ & $\times$ & $\sqrt{ }$ & $\times$ & $\sqrt{ }$ \\
\hline IPSL-CM5A-LR & $\sqrt{ }$ & $\sqrt{ }$ & $\sqrt{ }$ & $\sqrt{ }$ & $\sqrt{ }$ \\
\hline IPSL-CM5A-MR & $\sqrt{ }$ & $\sqrt{ }$ & $\sqrt{ }$ & $\sqrt{ }$ & $\sqrt{ }$ \\
\hline IPSL-CM5B-LR & $\sqrt{ }$ & $\times$ & $\sqrt{ }$ & $\times$ & $\sqrt{ }$ \\
\hline MIROC-ESM & $\sqrt{ }$ & $\sqrt{ }$ & $\sqrt{ }$ & $\sqrt{ }$ & $\sqrt{ }$ \\
\hline MIROC-ESM-CHEM & $\sqrt{ }$ & $\sqrt{ }$ & $\sqrt{ }$ & $\sqrt{ }$ & $\sqrt{ }$ \\
\hline MIROC5 & $\sqrt{ }$ & $\sqrt{ }$ & $\sqrt{ }$ & $\sqrt{ }$ & $\sqrt{ }$ \\
\hline MPI-ESM-LR & $\sqrt{ }$ & $\sqrt{ }$ & $\sqrt{ }$ & $\times$ & $\sqrt{ }$ \\
\hline MPI-ESM-MR & $\sqrt{ }$ & $\sqrt{ }$ & $\sqrt{ }$ & $\times$ & $\sqrt{ }$ \\
\hline MRI-CGCM3 & $\sqrt{ }$ & $\sqrt{ }$ & $\sqrt{ }$ & $\sqrt{ }$ & $\sqrt{ }$ \\
\hline NorESM1-M & $\sqrt{ }$ & $\sqrt{ }$ & $\sqrt{ }$ & $\sqrt{ }$ & $\sqrt{ }$ \\
\hline
\end{tabular}




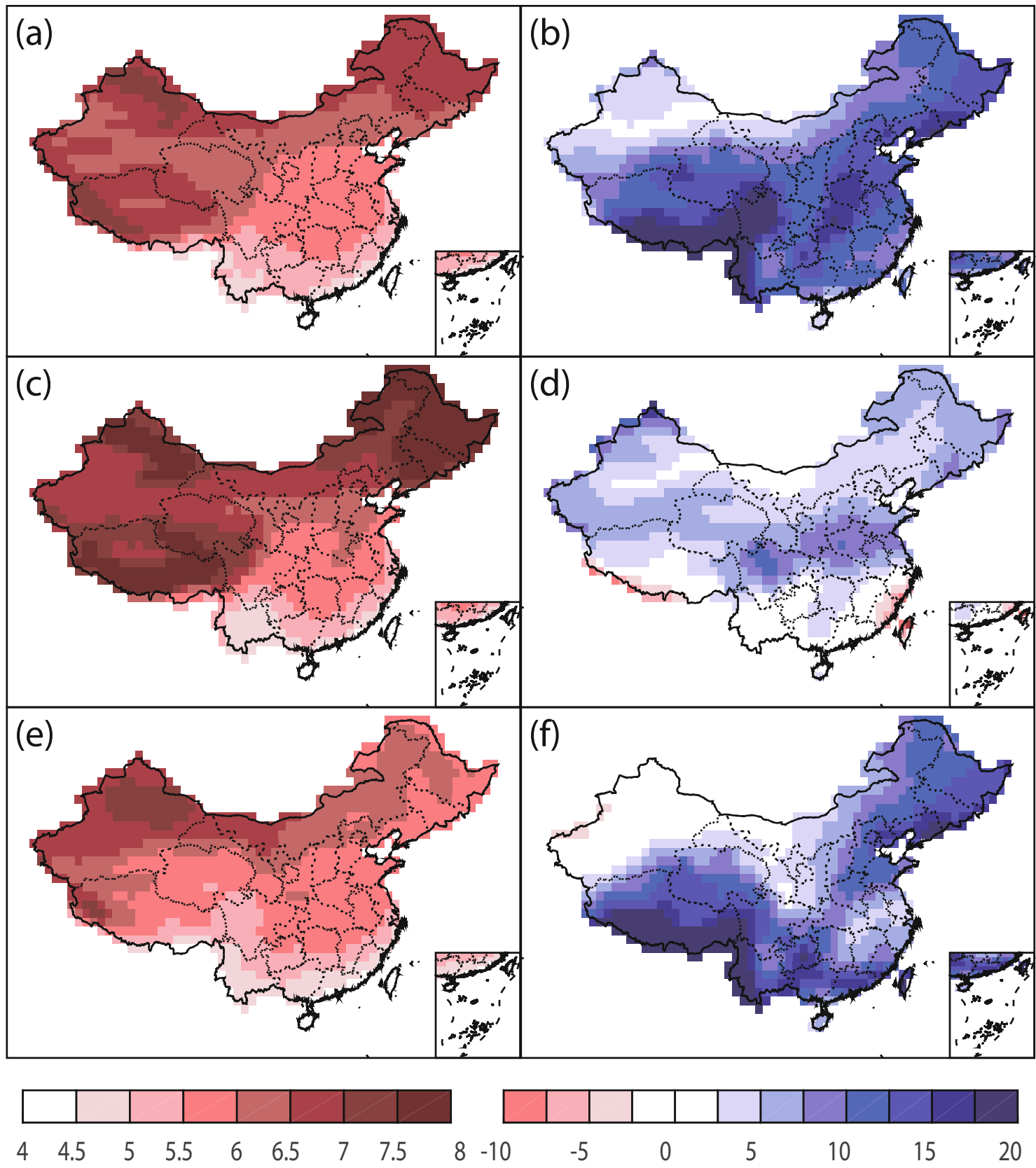

Fig. 1. Spatial distributions of multi-model mean linear trends $\left[{ }^{\circ} \mathrm{C}(110 \mathrm{yr})^{-1}\right.$ for temperature and (mm month $\left.{ }^{-1}\right)(110$ $y r)^{-1}$ for precipitation] in (a, b) annual, (c, d) winter (December-February), and (e, f) summer (June-August) mean (a, $\mathrm{c}$, e) temperature and (b, d, f) precipitation, under the RCP8.5 scenario during 1990-2100. Summer precipitation trends (f) have been divided by two to meet the range of the color scale.

only the output from one ensemble (r1i1p1) was used, so that all models were afforded equal weight.

\subsection{Data pretreatment}

The following pretreatments, which were also performed by Mahlstein et al. (2013) and Feng et al. (2014), were applied to both observed and simulated fields before computing the Köppen classes. First, the monthly grids of data were interpolated onto a $1^{\circ} \times 1^{\circ}$ grid to ensure the same resolution. Second, anomalies relative to the simulated monthly means for 1980-99 were calculated in each model and each of the four RCP scenarios, and were then added to the observed 1980-99 monthly means to reduce errors in the climate classification. This was necessary because the KöppenGeiger climate classification scheme is highly sensitive to thresholds, and current models have temperature and precipitation biases that cause difficulties in simulating the correct Köppen classes, even for present conditions (Gnanadesikan and Stouffer, 2006; Mahlstein et al., 2013). Third, to emphasize trends rather than short-term climate variations that cause 
erratic climate zone movements, a 15-year running smoothing was applied to all CMIP5 grids (monthly grids were the averages of the same month of each year). Fifteen years is the optimal averaging interval for Köppen or related classifications (Fraedrich et al., 2001), but the present results were not highly sensitive to the length of the averaging period. In the rest of this paper, model-derived data for a "year" refers to a 15-year centered average, and the last available year of 2093 is the 2086-2100 average.

\subsection{Computing the Köppen classes}

Köppen-Geiger climate classes were determined using the criteria defined in Peel et al. (2007). The classification process first identifies five major climate types: A-tropical; B-dry (arid and semiarid); C-subtropical; D-continental; and E-polar. Type B is based on moisture availability, while the other types are based on annual temperature. Each major type has two or three subtypes, and each subtype in types B-D has two to four minor subtypes, all classified according to the seasonal cycle of temperature, precipitation, or both There are 30 possible climate types, and Table 2 lists the criteria for the 18 climate classes relevant to China. While types A, C, D and E are mutually exclusive temperature categories, any arid or semiarid location (Type B) also fits the temperature criteria of another climate type, so tests for Type B were performed first.

\subsection{Identifying anthropogenic changes}

The focus of this study was not on differences between models, so grids from all model runs in each scenario were averaged together. The pretreated monthly multi-model averaged temperature and precipitation grids (projected group) were then used to assign Köppen classes for each grid box and year from 1991 (1984-98 average) to 2093 (2086-2100 average), and the year of change (if any) of climate class from the 1990 base year (center year of observed 1980-99 climatology) was noted. Note that Köppen classification is based on climate values rather than anomalies.

Table 2. Köppen classes and corresponding climate/vegetation types in observations or projections over China.

\begin{tabular}{|c|c|c|c|c|}
\hline Type & Subtype & Long name & Criteria & Vegetation cover \\
\hline \multirow[t]{3}{*}{ A } & & Tropical & $T_{\text {cold }} \geqslant 18$ & \\
\hline & Am & Tropical monsoon & $P_{\mathrm{dry}}<60$ and $P_{\mathrm{dry}} \geqslant 100-\mathrm{MAP} / 25$ & Tropical seasonal forest \\
\hline & Aw & Tropical savanna & $P_{\text {dry }}<60$ and $P_{\text {dry }}<100-\mathrm{MAP} / 25$ & Savanna \\
\hline \multirow[t]{5}{*}{ B } & & Arid & MAP $<10 \times \mathrm{P}_{\text {threshold }}$ & \\
\hline & BWh & Hot arid & MAP $<5 \times P_{\text {threshold }}$ and MAT $\geqslant 18$ & Desert \\
\hline & BWk & Temperate arid & MAP $<5 \times P_{\text {threshold }}$ and MAT $<18$ & Desert \\
\hline & $\mathrm{BSh}$ & Hot semi-arid & $\mathrm{MAP} \geqslant 5 \times P_{\text {threshold }}$ and $\mathrm{MAT} \geqslant 18$ & Steppe \\
\hline & BSk & Temperate semi-arid & $\mathrm{MAP} \geqslant 5 \times P_{\text {threshold }}$ and $\mathrm{MAT}<18$ & Steppe \\
\hline \multirow[t]{4}{*}{$\mathrm{C}$} & & Temperate & $T_{\text {hot }}>10$ and $0<T_{\text {cold }}<18$ & \\
\hline & $\mathrm{Cfa}$ & Subtropical humid & $\begin{array}{l}\operatorname{Not}\left(P_{\text {sdry }}<40 \text { and } P_{\text {sdry }}<P_{\text {wwet }} / 3\right) \text { or }\left(P_{\text {wdry }}<\right. \\
\left.\quad P_{\text {swet }} / 10\right) \text { and } T_{\text {hot }} \geqslant 22\end{array}$ & Temperate broadleaved evergreen forest \\
\hline & Cwa & Subtropical winter dry & $P_{\text {wdry }}<P_{\text {swet }} / 10$ and $T_{\text {hot }} \geqslant 22$ & Temperate broadleaved evergreen forest \\
\hline & $\mathrm{Cwb}$ & $\begin{array}{l}\text { Temperate oceanic } \\
\text { Continental }\end{array}$ & $\begin{array}{l}P_{\text {wdry }}<P_{\text {swet }} / 10 \text { and } T_{\text {hot }}<22 \text { and } T_{\text {mon } 10} \geqslant 4 \\
T_{\text {hot }}>10 \text { and } T_{\text {cold }} \leqslant 0\end{array}$ & Temperate broadleaved evergreen forest \\
\hline \multirow{8}{*}{$\mathrm{D}$} & Dfa & Continental humid & $\begin{array}{c}\operatorname{Not}\left[P_{\text {sdry }}<40 \text { and } P_{\text {sdry }}<P_{\text {wwet }} / 3(\mathrm{Ds})\right] \text { or } \\
{\left[P_{\text {wdry }}<P_{\text {swet }} / 10(\mathrm{Dw})\right] \text { and } T_{\text {hot }} \geqslant 22}\end{array}$ & Temperate deciduous forest \\
\hline & $\mathrm{Dfb}$ & Continental humid & Not (Ds) or (Dw) and $T_{\text {hot }}<22$ and $T_{\operatorname{mon} 10} \geqslant 4$ & Temperate and boreal mixed forest \\
\hline & Dfc & Sub-polar humid & $\begin{array}{l}\text { Not (Ds) or (Dw) and } T_{\text {hot }}<22 \text { and } T_{\operatorname{mon} 10}<4 \\
\text { and } T_{\text {cold }}>-38\end{array}$ & Boreal conifer forest/woodland \\
\hline & Dwa & Continental winter dry & $P_{\text {wdry }}<P_{\text {swet }} / 10$ and $T_{\text {hot }} \geqslant 22$ & Temperate deciduous forest \\
\hline & Dwb & Continental winter dry & $P_{\text {wdry }}<P_{\text {swet }} / 10$ and $T_{\text {hot }}<22$ and $T_{\text {mon } 10} \geqslant 4$ & Temperate/boreal mixed forest \\
\hline & Dwc & Sub-polar winter dry & $\begin{array}{l}P_{\text {wdry }}<P_{\text {swet }} / 10 \text { and } T_{\text {hot }}<22 \text { and } T_{\text {mon } 10}<4 \\
\quad \text { and } T_{\text {cold }}>-38\end{array}$ & Boreal deciduous forest/woodland \\
\hline & Dsb & Continental summer dry & $\begin{array}{l}P_{\text {sdry }}<40 \text { and } P_{\text {sdry }}<P_{\text {wwet }} / 3 \text { and } T_{\text {hot }}<22 \text { and } \\
\quad T_{\text {mon } 10} \geqslant 4\end{array}$ & - \\
\hline & Dsc & Sub-polar summer dry & $\begin{array}{l}P_{\text {sdry }}<40 \text { and } P_{\text {sdry }}<P_{\text {wwet }} / 3 \text { and } T_{\text {hot }}<22 \text { and } \\
T_{\text {mon } 10}<4 \text { and } T_{\text {cold }}>-38\end{array}$ & - \\
\hline \multirow[t]{2}{*}{$\mathrm{E}$} & & Polar & $T_{\text {hot }}<10$ & \\
\hline & ET & Alpine climate & $T_{\text {hot }}>0$ & Alpine tundra/polar desert \\
\hline
\end{tabular}

All precipitation amounts are in $\mathrm{mm}$ and all temperatures are in ${ }^{\circ} \mathrm{C} . \mathrm{MAP}=$ mean annual precipitation; MAT $=$ mean annual temperature; $T_{\text {hot }}=$ temperature of the hottest month; $T_{\text {cold }}=$ temperature of the coldest month; $T_{\operatorname{mon} 10}=$ number of months where the temperature is above $10 ; P_{\text {dry }}=$ precipitation of the driest month; $P_{\text {sdry }}=$ precipitation of the driest month in summer; $P_{\mathrm{wdry}}=$ precipitation of the driest month in winter; $P_{\text {swet }}=$ precipitation of the wettest month in summer; $P_{\text {wwet }}=$ precipitation of the wettest month in winter; $P_{\text {threshold }}$ varies according to the following rules: if $70 \%$ of MAP occurs in winter, then $P_{\text {threshold }}=2 \times$ MAT; if $70 \%$ of MAP occurs in summer, then $P_{\text {threshold }}=2 \times$ MAT +28 ; otherwise, $P_{\text {threshold }}=2 \times$ MAT +14 . For China, summer is defined as April-September, and winter is October-March (Peel et al., 2007). 
To distinguish and eliminate possible natural fluctuations in climate zones, the naturally occurring climate shifts in a grid box were identified using detrended 15-year smoothed temperature and precipitation ("natural group") (Mahlstein et al., 2013). In the natural group, the atmospheric fields were first detrended over 1950-2005 and 2006-2100, separately, and then pretreated using the same interpolation, adjustment and smoothing methods as in section 2.2. Since there were no trends in the natural group, the distribution of climate zones in the natural group should mainly resemble those based on observed 1980-99 climatology, indicating the projection of no significant changes in climate types in the natural group.

By comparing with the natural group, we counted a human-induced change in climate type for a particular grid point in the "projected group" under two circumstances: (1) A new climate type never found in the natural group emerged, and its time of emergence was the first year it was identified. (2) A new climate type-which could also be found in the natural group, but would shift back to its original class quickly due to short-term variability-that persisted until at least 2100, or changed to another new climate type. Its emerging time was the first year when this new climate type in the projected group differed from that in the natural group. Changes counted under the second circumstance indicated irreversible human-induced shifts in climate types, and were commonly found over transient zones.

All changes of climate zones counted were caused by increasing anthropogenic forcing. In other words, naturalinduced temporary changes in the projected group were omitted through further analyses. Finally, the percentage of land area covered by each climate type was computed by areaweighting all grid boxes by the cosine of their latitude.

\section{Results}

\subsection{Projected climate changes}

The multi-model ensemble-mean warming and precipitation trends during 1990-2100 under the RCP8.5 scenario (Fig. 1) are consistent with a previous study by $\mathrm{Xu}$ and $\mathrm{Xu}$ (2012). Three centers of warming are located over Northeast and Northwest China, and the Tibetan Plateau (Fig. 1a), with generally more warming in winter than in summer (Figs. 1c and e). The projected annual precipitation increases over all of China (Fig. 1b). Despite Southeast China currently being the wettest region, small increases are expected there, with a band of increased precipitation extending from inland southeastern China to northeastern China. The largest precipitation increase, however, is expected in southwestern China, including part of the Tibetan region into central China, an area that is currently moderately dry. The above-mentioned increase in precipitation occurs mostly in summer (Fig. 1f). Reduced wintertime precipitation is found over Southwest and Southeast China, and the Himalaya (Fig. 1d). The spatial distributions under the other scenarios, though showing smaller amplitude, are similar to those under RCP8.5 (figures not shown).

\subsection{Projected shifts in climate types}

Figure 2a shows the 1990 base year Köppen classes over China, and encompasses 13 subtypes from all 5 basic types. Table 2 lists the Köppen classes observed or projected in China from Peel et al. (2007), as well as their corresponding climate (Shi et al., 2012) and general vegetation types (Hou et al., 1982). There is a small area of tropical climate (Am) in the far south of China, while deserts (Bw) and steppe (Bs) are dominant over northwestern China. Temperate climate (C), mainly including three subtypes [humid (Cfa), subtropical winter dry (Cwa), and oceanic climate (Cwb)], is found over Southwest and southeastern China. North and Northeast China are mainly characterized by continental humid climate (Dwa and Dwb), while sub-polar climate (Dwc) is detectable over the northernmost region. Finally, alpine climate (ET) dominates the central and southwestern Tibetan Plateau, while continental climate (mainly Dwb and Dwc) is found over the eastern and southern Tibetan Plateau and arid climate (mainly BWk and BSk) is found over the western and northern Tibetan Plateau. The coverage of the major climate types A-E in 1990 is about $0.5 \%, 29.7 \%, 27.9 \%, 32.1 \%$ and $9.8 \%$ of the total land area, respectively. Such distributions of present-day Köppen classifications are consistent with regional climate types over China in global studies by Peel et al. (2007) and Rubel and Kottek (2010), and reflect the vegetation map of Hou et al. (1982) fairly well, which indicates that the Köppen climate types are well able to capture signals of eco-climate regions in China.

The projected climate types for 2093 derived from multimodel averages are shown in Figs. 2b-e. Under the low emissions scenario (RCP2.6), the most conspicuous changes are found over Northeast China, characterized by shifts of Dwc to Dwb and Dwb to Dwa, and also over the Tibetan Plateau, characterized by shifts of ET to Dwc and Dwc to Dwb. Other changes include a northwestward retreat of $\mathrm{Cwb}$ associated with an expansion of Cwa in Southwest China, and a northward expansion of Cwa and Cfa over East and Central China.

These changes are larger under the intermediate emissions scenarios (RCP4.5 and RCP6), including the further reduction of Dwb and the disappearance of Dwc in Northeast China, the replacement of ET with transitional boreal forest (Dwc and Dwb) in the eastern and southern parts of the Tibetan Plateau due to increasing summertime temperature (Fig. 1e), and a great shrinkage of Cfa in Southeast China mainly caused by decreasing precipitation in winter. Dramatic changes are found under the high emissions scenario (RCP8.5), characterized by the disappearance of Dwb in Northeast China (replaced by Dwa), the disappearance of ET on the Tibetan Plateau (replaced by Dwb and Dwc in southern and eastern parts, and BSk in the northwestern part), a vast shrinkage of Cfa over southeastern China, the emergence of Bwa (hot desert climate) in Northwest China, and an extension of Aw (tropical savanna) reaching the nearby coast in South China.

Higher emissions cause greater eco-climate impacts. By the end of the 21 st century, about $22.5 \%, 37.3 \%, 47.0 \%$ and 


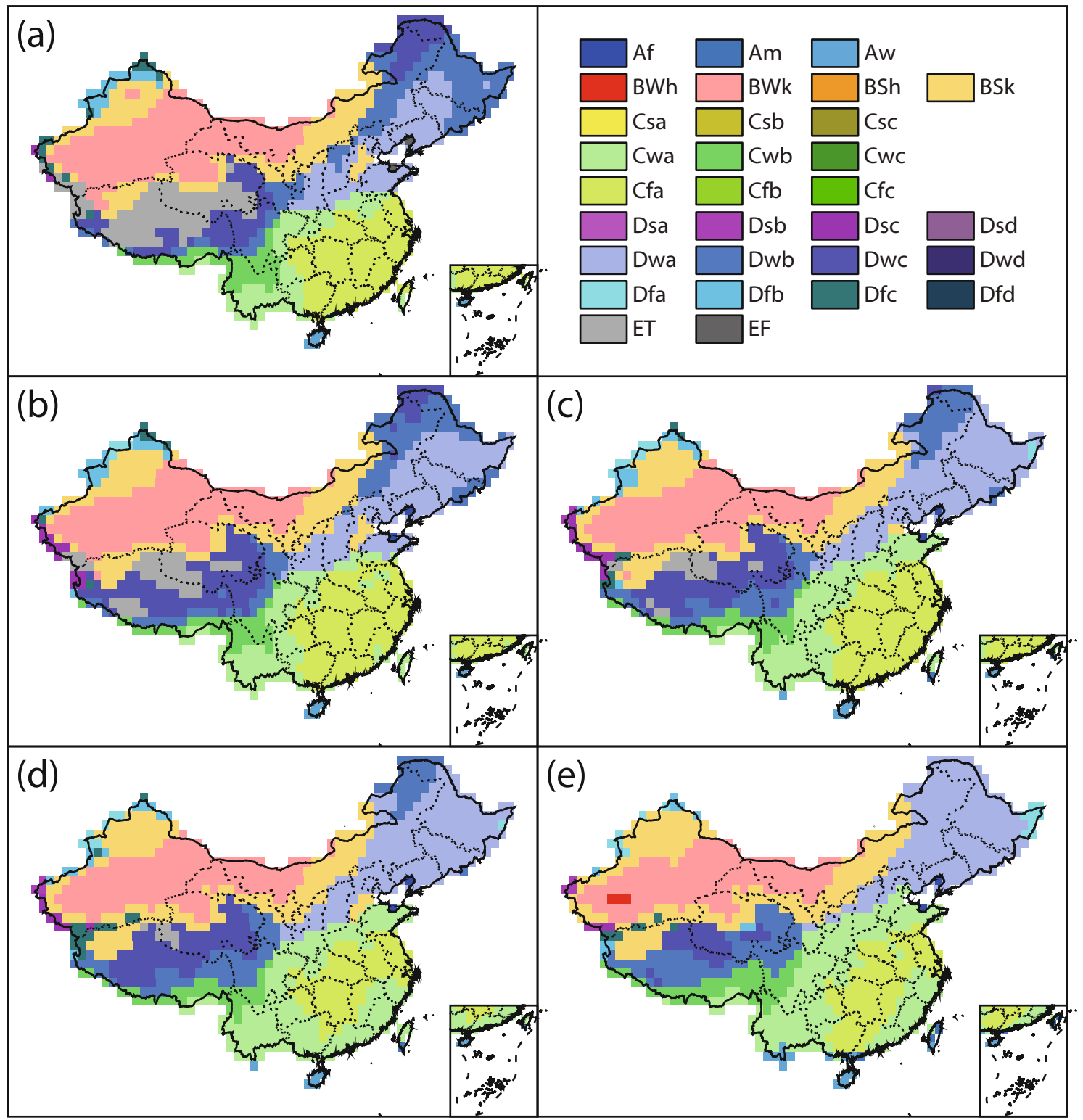

Fig. 2. Spatial distribution of Köppen classes over China in the 1990 base year, computed from (a) observed data, and derived from multi-model averaged projections for 2093 under the RCP (b) 2.6, (c) 4.5, (d) 6 and (e) 8.5 scenarios.

$50.8 \%$ of China's total land area is projected to undergo anthropogenic changes (compared with 1990 types) under the RCP2.6, 4.5, 6 and 8.5 scenarios, respectively. Projected areas, by 2093 , are $29.1 \%, 28.4 \%, 28.1 \%$ and $30.6 \%$ for type B, $30.1 \%, 32.8 \%, 32.9 \%$ and $36.4 \%$ for type C, $35.7 \%, 36.0 \%$, $37.0 \%$ and $31.1 \%$ for type D, and $4.7 \%, 2.2 \%, 0.7 \%$ and $0 \%$ for ET (Figs. 3b-e). Under the RCP8.5 scenario, the changes in the present study (Fig. 2e) agree with regional results over China in the global studies by Rubel and Kottek (2010) and Feng et al. (2014), and the subtype changes over eastern China are generally consistent with the findings of Shi et al. (2012).

\subsection{Temporal evolution of climate shifts in China}

Figure 3 shows time series from 1990 to 2093 of the percentage of China's land area seeing changes in Köppen classes compared with 1990, and the percentages occupied by the major climate types B-E and certain C and D subtypes. In the historical period (2010 compared to 1990), anthropogenic influence is already detectable, with strong expansion (contraction) in type D (ET) climate and weak expansion (contraction) in type $\mathrm{C}(\mathrm{B})$ climate, causing climate type changes in about $7 \%-8 \%$ of national land area. Under the RCP2.6, 4.5, 6 and 8.5 scenarios, about $21.4 \%, 27.4 \%$, $24.3 \%$ and $35.9 \%$, respectively, of total land area is projected to undergo a change in 2050 compared to 1990.

The year when an anthropogenic-induced change in ecoregions, compared to the 1990 base year, first emerges in each grid box for each scenario is shown in Fig. 4. As can be seen, there is considerable spatial variation in the emergence of changes in Köppen climate types. First, the changes in Köppen climate types before 2010 are mainly seen in transi- 

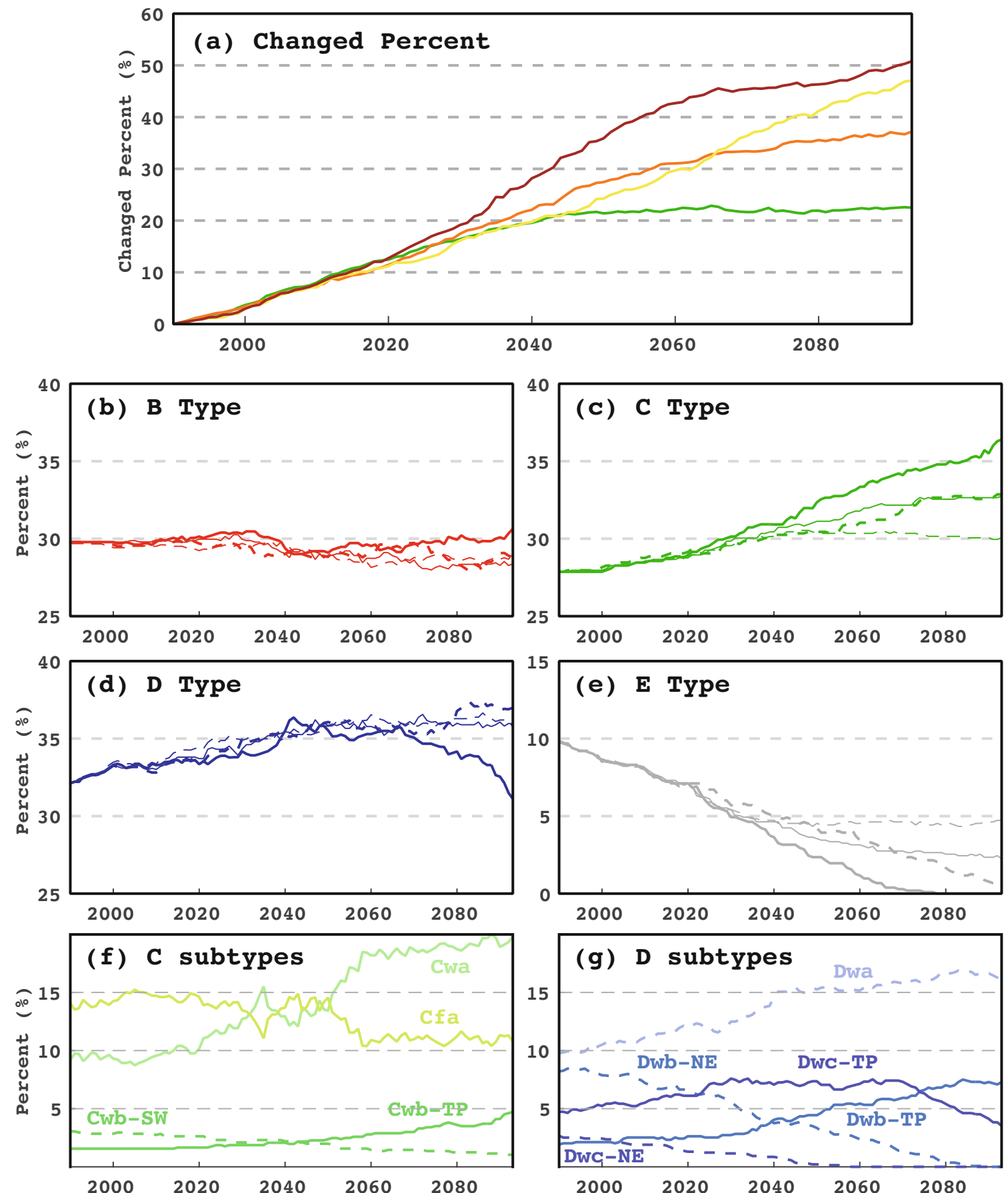

Fig. 3. (a) Time series of percentage changes in Köppen classes over the national land area (green line, RCP2.6; orange line, RCP4.5; yellow line, RCP6.0; red line, RCP8.5). (b-e) Total area occupied by each of the major climate types B-E, respectively (thin solid lines, RCP2.6; thin dashed lines, RCP4.5; thick dashed lines, RCP6.0; thick solid lines, RCP8.5. (f, g) Time series of areas (\%) in three sub-types of the major climate types $\mathrm{C}$ and $\mathrm{D}$, respectively, under the RCP8.5 scenario. Temperate ocean climate (Cwb) over Southwest China (SW) and the Tibetan Plateau (TP), and two continental winter dry climate types (Dwa and Dwb) over Northeast China (NE) and the TP, are plotted separately.

tion zones between the present Köppen climate types shown in Fig. 2a. These changes are associated with the shift from Dwb to Dwa in Northeast China, the northwestward retreat of Cwb in Southwest China, the northward expansion of Cwa over northern Central and East China, and the shift from ET to Dwc over the margins of the Tibetan Plateau. Second, these ongoing shifts continue at a northward or westward pace from transition zones. Northwest China and the Tibetan Plateau are two regions most sensitive to projected warming in the ensuing decades. Rapid changes of Dwb to Dwa in Northeast China, and strong shrinkage of ET on the Tibetan Plateau are projected before 2030-40 under the RCP4.5 or higher scenar- 
ios (Figs. 4b-e). The projected area of ET is less than $5.0 \%$ of the national land area by 2040 (Fig. 3e). Third, the annual percentage decrease of ET is projected to increase substantially after 2010. The relative area of ET decreases by about $1.7 \%$ during 1990-2010, but is projected to decrease by about $2.7 \%, 2.7 \%$, and $2.4 \%$ and $3.1 \%$ of China's land area during 2010-30 under the RCP2.6, 4.5, 6 and 8.5 scenarios, respectively (Fig. 3e). Fourth, the pace of northward or westward shifts in climate zones increases under high RCP scenarios after 2030-40. For these grid boxes away from transition zones, projected climate shifts tend to emerge earlier under the higher RCP scenarios. For instance, most shifts from Dwc to Dwb over northern Northeast China are projected to happen by around 2040-50 under RCP8.5; whereas, under RCP4.5, it is projected to happen by around 2050-70. Similar advances by $20-30$ years in emerging anthropogenic signals can also be found in the northward shift of temperate forests (Cwa and Cfa) over northern East China, the change of ET to Dwb on the Tibetan Plateau, the shrinkage of oceanic climate (Cwb) in Southwest China, and the shifts of Cfa to Cwa in Southeast China. Finally, the coverage of type-B climate is projected to be about $28 \%-30 \%$ throughout the 21 st century under all scenarios (Fig. 3b), and the replacement of Cwa by Aw over South China occurs near the end of the 21 st century under the RCP8.5 scenario only (Fig. 4d).

We further investigated the temporal evolution of land area covered by six sub-types of major type-C and type-D under the RCP8.5 scenario (Figs. $3 \mathrm{f}$ and g). The coverage of temperate climate increases from the northward and westward expansion of Cwa and Cwb (Fig. 3c). Cwb is projected to decrease in Southwest China, but increase over the Tibetan Plateau (Fig. 3f). The evolutions of sub-type climate Cwa and Cfa over eastern China exhibit considerable variability, but the projected coverage of Cwa ( $\mathrm{Cfa}$ ) shows a strong increase (decrease) during 2035-55. The coverage of temperate climate increases by about $4.5 \%$ and $8.5 \%$ by 2050 and 2093 , respectively (Fig. 3c). As climate change accelerates, Dwc is rapidly replaced by Dwb over Northeast China before 2050, and primarily confined to over the Tibetan Plateau after 2050. The annual percentage decrease of Dwb in Northeast China is projected to increase substantially after 2010 . The coverage of Dwb is projected to be about $8.1 \%, 7.0 \%, 5.4 \%, 3.3 \%$ and $1.4 \%$ in 1990, 2010, 2030, 2050, and 2070, respectively, and decrease by about $1.1 \%, 1.6 \%, 2.1 \%, 1.9 \%$ of China's land area during 1990-2010, 2010-30, 2030-50, and 205070 , respectively (Fig. 3g). The coverage of Dwa is projected to increase to $15.3 \%(16.1 \%)$ in 2050 (2093) from $9.8 \%$ in 1990, suggesting that the expansion of Dwa will mostly fin-

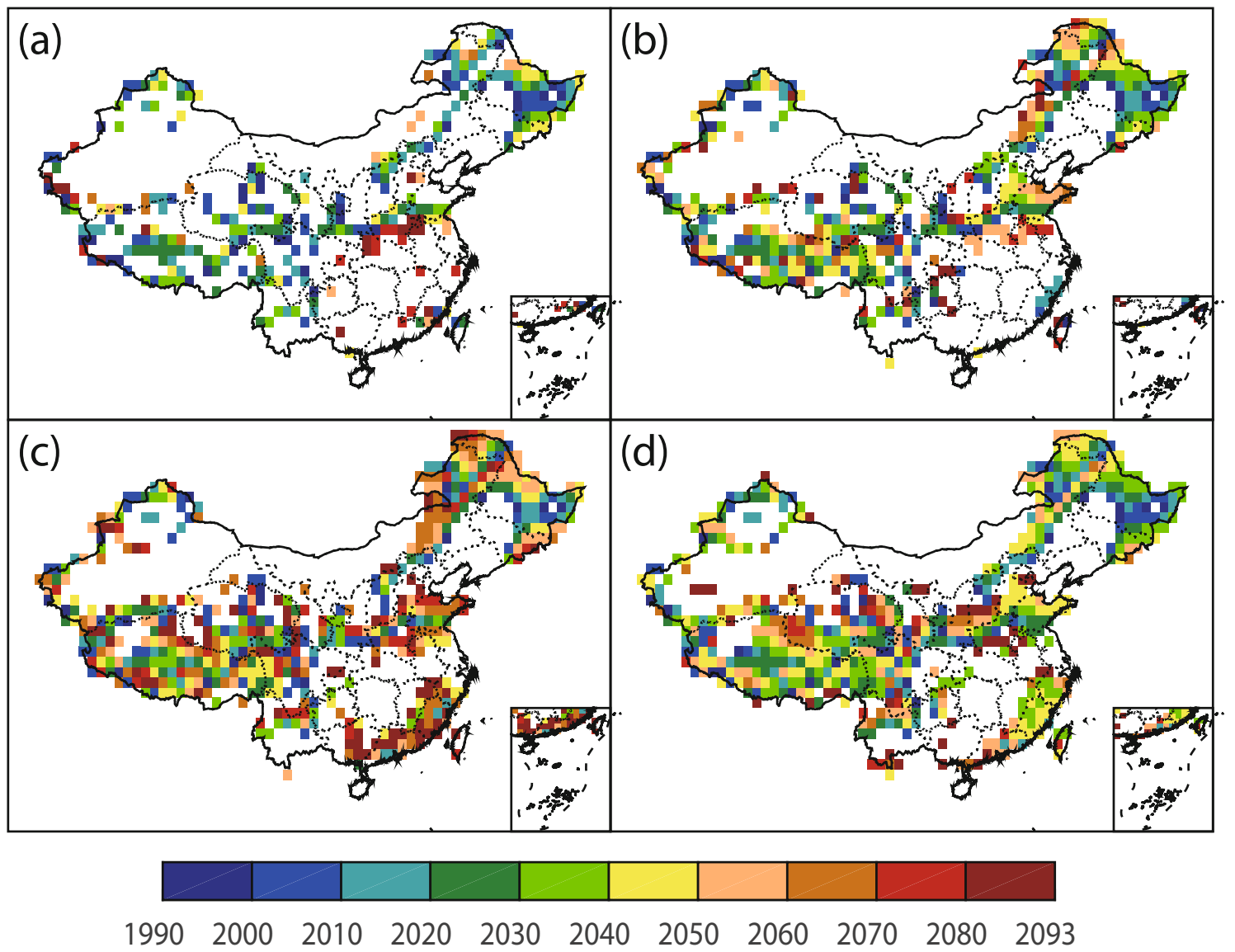

Fig. 4. Maps showing the times of first emergence - the year a specific grid box undergoes a human-induced shift in climate zones for the first time- under (a) RCP2.6, (b) RCP4.5, (c) RCP6.0 and (d) RCP8.5. White areas denote that no anthropogenic changes occur until the end of the 21st century (2086-2100 due to 15-year smoothing). 
ish before 2050. The projected decrease of the total area of type-D climate after 2070 shown in Fig. 3d is mainly due to the shift of Dwc to Dwb and Dwb to Cwb on the Tibetan Plateau (Figs. 3f and g).

\subsection{Relative roles of temperature and precipitation in cli- mate shifts}

Most changes in climate types over China seem to be temperature rather than precipitation driven. Figure 5 shows the spatial distributions of projected Köppen classes for 2093, calculated by the changes in individual variables under the RCP8.5 scenario. Most of the climate shifts apparent in Fig. $2 \mathrm{e}$ are reproduced if precipitation is held constant, while only the present-day distribution in Fig. 2a is broadly captured when the temperature is fixed. Similar results have been discussed in previous vegetation model studies (Zhang and Zhou, 2008; Wang et al., 2011).

Figure 5 also reveals that the area of arid climate increases (decreases) with growth in temperature (precipitation) over North and Northwest China, suggesting that water and heat factors play opposite roles for arid climate (type B). These two offsetting effects may explain why the coverage of type$\mathrm{B}$ (arid) climate shows no significant changes in the 21 st century even under the RCP8.5 scenario (Fig. 2e). In addition, Fig. 5b confirms that decreasing winter precipitation causes the reduction of subtropical humid Cfa in southeastern China (Shi et al., 2012), while increasing temperature results in the northwestward retreat of Cwb in Southwest China.

\section{Conclusions}

The Köppen classification schemes were developed to predict the biome distribution by combining temperature and precipitation, and their seasonality, into one matrix. Although such bioclimatic classification schemes have some disadvantages, such as the lack of wind, sunshine and $\mathrm{CO}_{2}$ effects as contributing factors to shifting biome patterns, previous studies have suggested that the Köppen climate types are largely successful in their resemblance of the major vegetation types (Baker et al., 2010).

The aim of the present study was to extend previous gen- eral studies on observed and projected climate shifts in China, by performing a detailed investigation of the temporal evolution of Köppen-Geiger climate types over the national land area using observational data and simulations from multiple global climate models participating in CMIP5. The projected changes of climate types by 2100 generally agree with previous studies using Köppen or related climate classifications (Baker et al., 2010; Rubel and Kottek, 2010; Shi et al., 2012; Feng et al., 2014), and studies with specialized vegetation models driven by climate model outputs (Ni et al., 2000; Zhao and Wu, 2014; Wang, 2014; Cho et al., 2015). However, the following specific findings suggest that impacts of anthropogenic climate change on regional climate zones are already evident and are expected to accelerate, under all future scenarios, before 2050 .

(1) The magnitudes of the impacts of warming and the pace of shifts were found to be similar before 2030, but larger under higher emissions scenarios thereafter. The proportion of the national land area experiencing changes in climate types increased gradually from about $7 \%-8 \%$ in 2010 to about $22.5 \%, 37.3 \%, 47.0 \%$ and $50.8 \%$ by the end of this century under the RCP2.6, 4.5, 6 and 8.5 scenarios, respectively.

(2) Northeast China was found to be one of the regions most sensitive to increasing warming in the first half of this century. The pace of the shift of Dwb to Dwa, corresponding to the replacement of temperate/boreal mixed forest by temperate deciduous forest (Ni et al., 2000; Leng et al., 2008; $\mathrm{Ni}, 2011$ ), is expected to significantly increase in the coming decades. Under the RCP8.5 scenario, Dwc (boreal forest) disappeared over northern Northeast China by around 2040 50 .

(3) The Tibetan Plateau is another sensitive region whose biome system is expected to face more exposure and risks related to future climate change, with the disappearance of the current alpine climate area by 2070 under the RCP8.5 scenario. The loss of alpine climate was concentrated in the period $2010-30$, and its projected area was under $5 \%$ by 2040 under all scenarios, implying that the impacts of climate changes over this region will accelerate in the near future. There is likely to be a major westward and northward shift

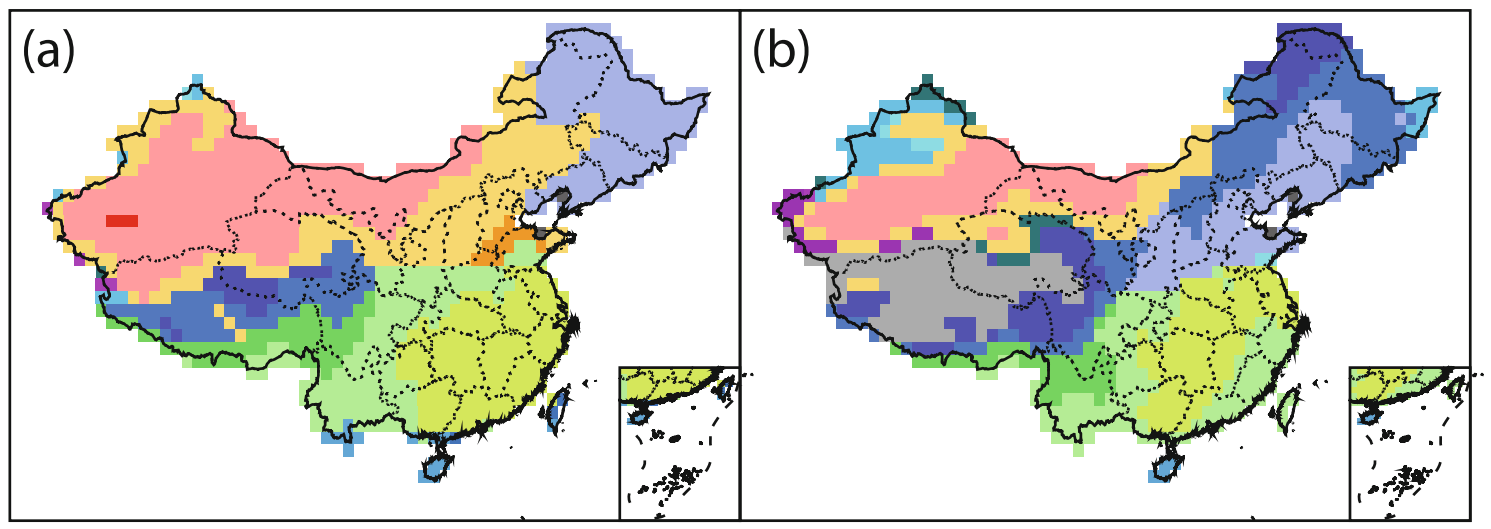

Fig. 5. As in Fig. 2e but with trends of (a) precipitation or (b) temperature, removed. 
of boreal deciduous forest/woodland and alpine meadow, and a major reduction in alpine tundra/polar desert (Song et al., 2005; Ni, 2011).

(4) The region of temperate climate (C), under all four scenarios, was projected to expand due to the northwestward shift of subtropical winter dry (Cwa) over eastern China and the increase of temperate ocean climate $(\mathrm{Cwb})$ over the Tibetan Plateau. A northward and westward expansion of Cwa over Central and East China was found to be associated with a northwestward retreat of Cwb in Southwest China, under all four scenarios. A rapid shrinkage of subtropical humid (Cfa) in East China was projected for the period 2035-55 due to the decrease in winter precipitation under the RCP8.5 scenario.

Although caution should be applied while using the Köppen-Geiger classification method to interpret vegetation changes, the present results nevertheless indicate significant impacts of anthropogenic climate change on ecoregions over the Tibetan Plateau and Northeast China-sensitive regions whose biome system is expected to face more exposure and risks related to climate change in the near future. When a climate threshold is passed, the existing vegetation will be less suited to the changed environment, and changes in vegetation can jeopardize the habitats of the wildlife that depends on those plant communities.

Acknowledgements. We acknowledge the Physical Sciences Division (PSD) group for providing the UDel_AirT_Precip data. We also acknowledge all participants of CMIP5 for producing and making available their model outputs. This work was supported by the National Key Scientific Research Plan of China (Grant No. 2012CB956002) and the National Natural Science Foundation of China (Grant No. 41075052).

\section{REFERENCES}

Almorox, J., V. H. Quej, and P. Martí, 2015: Global performance ranking of temperature-based approaches for evapotranspiration estimation considering Köppen climate classes. $J$. Hydrol., 528, 514-522.

Baker, B., H. Diaz, W. Hargrove, and F. Hoffman, 2010: Use of the Köppen-Trewartha climate classification to evaluate climatic refugia in statistically derived ecoregions for the People's Republic of China. Climatic Change, 98, 113-131.

Chan, D., and Q. G. Wu, 2015: Significant anthropogenic-induced changes of climate classes since 1950. Sci. Rep., 5, 13487.

Cho, M.-H., K. -O. Boo, G. M. Martin, J. Lee, and G.-H. Lim, 2015: The impact of land cover generated by a dynamic vegetation model on climate over East Asia in present and possible future climate. Earth Sys. Dynam., 6(1), 147-160.

De Castro, M., C. Gallardo, K. Jylha, and H. Tuomenvirta, 2007: The use of a climate-type classification for assessing climate change effects in Europe from an ensemble of nine regional climate models. Climatic Change, 81, 329-341.

Engelbrecht, C. J., and F. A. Engelbrecht, 2015: Shifts in KöppenGeiger climate zones over southern Africa in relation to key global temperature goals. Theor. Appl. Climatol., doi: 10.1007/s00704-014-1354-1.

Feng, S., Q. Hu, W. Huang, C.-H. Ho, R. P. Li, and Z. H. Tang,
2014: Projected climate regime shift under future global warming from multi-model, multi-scenario CMIP5 simulations. Global Planet. Change, 112, 41-52.

Fraedrich, K., F.-W. Gerstengarbe, and P. C. Werner, 2001: Climate shifts during the last century. Climatic Change, 50, 405417.

Gnanadesikan, A., and R. J. Stouffer, 2006: Diagnosing atmosphere-ocean general circulation model errors relevant to the terrestrial biosphere using the Köppen climate classification. Geophys. Res. Lett., 33, L22701.

Hou, X. Y., S. Sun, J. Zhang, M. He, Y. Wang, D. Kong, and S. Wang, 1982: Vegetation Map of the People's Republic of China. China Cartography Press, Beijing. (in Chinese)

Köppen, W., 1936: Das geographisca system der klimate. Handbuch der Klimatologie, W. Köppen, G. Geiger, Eds., Borntraeger, 1-44.

Legates, D. R., and C. J. Willmott, 1990a: Mean seasonal and spatial variability in global surface air temperature. Theor. Appl. Climatol., 41, 11-21.

Legates, D. R., and C. J. Willmott, 1990b: Mean seasonal and spatial variability in gauge-corrected, global precipitation. Int. J. Climatol., 10, 111-127.

Leng, W. F., H. S. He, R. C. Bu, L. M. Dai, Y. M. Hu, and X. G. Wang, 2008: Predicting the distributions of suitable habitat for three larch species under climate warming in Northeastern China. For. Eco. Manag., 254, 420-428.

Ma, J., Y. M. Hu, R. C. Bu, Y. Chang, H. W. Deng, and Q. Qin, 2014: Predicting impacts of climate change on the aboveground carbon sequestration rate of a temperate forest in northeastern China. PLoS one, 2014, 9(4), e96157.

Mahlstein, I., J. S. Daniel, and S. Solomon, 2013: Pace of shifts in climate regions increases with global temperature. Nature Climate Change, 3, 739-743.

Ni, J., 2011: Impacts of climate change on Chinese ecosystems: Key vulnerable regions and potential thresholds. Reg. Environ. Change, 11, 49-64.

Ni, J., M. T. Sykes, I. C. Prentice, and W. Cramer, 2000: Modelling the vegetation of China using the process-based equilibrium terrestrial biosphere model BIOME3. Global Ecol. Biogeogr., 9, 463-479.

Pan, S., H. Q. Tian, C. Q. Lu, S. R. S. Dangal, and M. L. Liu, 2015: Net primary production of major plant functional types in China: Vegetation classification and ecosystem simulation. Acta Ecol. Sin., 35(2), 28-36.

Peel, M. C., B. L. Finlayson, and T. A. McMahon, 2007: Updated world map of the Köppen-Geiger climate classification. $H y$ drol. Earth Syst. Sci., 4, 439-473.

Peterson, T. C., R. Vose, R. Schmoyer, and V. Razuvaëv, 1998: Global historical climatology network (GHCN) quality control of monthly temperature data. Int. J. Climatol., 18, 11691179 .

Phillips, T. J., and C. J. W. Bonfils, 2015: Köppen bioclimatic evaluation of CMIP historical climate simulations. Environ. Res. Lett., 10, 064005.

Rohli, R. V., T. A. Joyner, S. J. Reynolds, C. Shaw, and J. R. Vázquez, 2015: Globally extended Köppen-Geiger climate classification and temporal shifts in terrestrial climatic types. Phys. Geogr., 36, 142-157.

Rubel, F., and M. Kottek, 2010: Observed and projected climate shifts 1901-2100 depicted by world maps of the KöppenGeiger climate classification. Meteorol. Z., 19, 135-141.

Shi, Y., X. J. Gao, and J. Wu, 2012: Projected changes in Köppen 
climate types in the 21 st century over China. Atmos. Oceanic Sci. Lett., 5, 495-498.

Song, M. H., C. P. Zhou, and H. Ouyang, 2005: Simulated distribution of vegetation types in response to climate change on the Tibetan Plateau. J. Veg. Sci., 16, 341-350.

Taylor, K. E., R. J. Stouffer, and G. A. Meehl, 2012: An overview of CMIP5 and the experiment design. Bull. Amer. Meteor. Soc., 93, 485-498.

Van Vuuren, D. P., and Coauthors, 2011: The representative concentration pathways: An overview. Climatic Change, 109, 531.

Wang, H., 2014: A multi-model assessment of climate change impacts on the distribution and productivity of ecosystems in China. Reg. Environ. Change, 14, 133-144.

Wang, H., J. Ni, and I. C. Prentice, 2011: Sensitivity of potential natural vegetation in China to projected changes in temperature, precipitation and atmospheric $\mathrm{CO}_{2}$. Reg. Environ. Change, 11, 715-727.

Wang, M. Y., and J. E. Overland, 2004: Detecting Arctic cli- mate change using Köppen climate classification. Climatic Change, 67, 43-62.

Xie, Z. H., F. Yuan, Q. Y. Duan, J. Zheng, M. L. Liang, and F. Chen, 2007: Regional parameter estimation of the VIC land surface model: Methodology and application to river basins in China. J. Hydrometeorol., 8, 447-468.

$\mathrm{Xu}, \mathrm{C} . \mathrm{H}$. , and $\mathrm{Y} . \mathrm{Xu}, 2012$ : The projection of temperature and precipitation over China under RCP scenarios using a CMIP5 multi-model ensemble. Atmos. Oceanic Sci. Lett., 5, 527-533.

Yu, L., M. K. Cao, and K. R. Li, 2006: Climate-induced changes in the vegetation pattern of China in the 21st century. Eco. Res., 21, 912-919.

Zhang, Y. J., and G. S. Zhou, 2008: Terrestrial transect study on driving mechanism of vegetation changes. Sci. China Ser. D, 51, 984-991.

Zhao, D. S., and S. H. Wu, 2014: Responses of vegetation distribution to climate change in China. Theor. Appl. Climatol., 117, $15-28$. 